\title{
Development of Insulating Refractory Ramming Mass from Some Nigerian Refractory Raw Materials
}

\author{
O. A. Olasupo ${ }^{1}$ and J. O. Borode ${ }^{2}$ \\ ${ }^{1}$ Engineering Infrastructure Department, \\ National Agency for Science and Engineering Infrastructure, \\ PMB 391, Garki, Abuja, Nigeria solayode@yahoo.com \\ ${ }^{2}$ Metallurgical and Materials Engineering Department, \\ The Federal University of Technology, Akure, Nigeria borode202@yahoo.co.uk \\ Corresponding Author: O. A. Olasupo solayode@yahoo.com
}

\begin{abstract}
Insulating refractory ramming mass was developed from suitable Nigerian refractory raw materials. Rammed samples from several ratios of clay, silica, mica, bentonite and calcium aluminate cement (Durax) were prepared using the American Foundrymen Society (AFS) standard rammer. They were thereafter tested for such properties as apparent porosity, volumetric firing shrinkage, cold compression strength, green compression strength, loss on ignition, thermal shock resistance and refractoriness. Results indicate that eight ramming cycles were just enough for the production of the ramming masses. Two optimal ratios obtained from the experiments have a refractoriness of $1500^{\circ} \mathrm{C}$, good compression strength and excellent thermal shock resistance. They are therefore recommended for lining of rotary furnaces and crucible furnaces for the melting of ferrous and non-ferrous alloys. It could be concluded that the ramming mass serve as a viable alternative to foreign ramming mass at the same temperature application.
\end{abstract}

\section{INTRODUCTION}

A refractory material is one that can withstand the action of abrasive or corrosive solids, liquids or gases at a high service temperature. They are classified according to shapes and chemical compositions. Classifying according to shape, there are shaped bricks and the monolithic refractories. Monolithic refractories are refractory materials that are single piece casts. They have advantages of eliminating joints which is an inherent weakness of refractory bricks linings. They have faster application methods, requires no special skill for installation and easy to transport 
and handle. They also have better spalling resistance and have greater volume stability, with considerable heat savings than the refractory bricks.

Monolithic refractories are put into place using various methods, such as ramming, casting, gunning, spraying, and sand slinging. Ramming requires proper tools and is mostly used in cold applications where proper consolidation of the material is important. Ramming is also used for air setting and heat setting materials. Because calcium aluminate cement is the binder, it will have to be stored properly to prevent moisture absorption. Its strength starts deteriorating after 6 to 12 months (UNEP, 2006).

Some earlier works on Nigerian refractories include that of Borode et al (2000) on the suitability of some Nigerian clay as refractory raw materials. Hassan (2001) worked on the effect of silicon carbide on some refractory properties of Kankara Clay. Nnuka and Apeh, (1991) worked on the characterization of Ukpor clay deposits while Nnuka and Okunoye, (1991) worked on the industrial potentials of the same deposit. Onyemaobi (2004), worked on the assessment of some refractory properties of some local clays for foundry usage. Ugheoke Onche, Namessan, and Asikpo (2006), assessed the property optimization of kaolin-rice husk insulating fire - bricks.

All these works have been centered on the production of refractory bricks from the raw materials. This present work however serves to develop a monolithic ramming mass from some Nigerian refractory raw materials using bentonite and calcium aluminate cement (Durax brand from Vesuvius Inc., USA) as binders.

\section{EXPERIMENTAL PROCEDURE}

The refractory materials used for the various mixes are clay from Ikere-Ekiti, Ekiti State, southwest Nigeria, silica (coarse-grained), mica from Ijero Ekiti, southwest Nigeria, Bentonite and calcium aluminate cement (Durax brand from Vesuvius Inc. USA) as binders.

\subsection{Equipment}

The main equipment used for the preparation and evaluation of the ramming mass properties includes jaw crusher, ball mill, sieve shaker, sand mixer, AFS ramming machine, Vecstar Electric furnace, Universal sand testing machine and cold compression strength tester.

\subsection{Methodology}

The as-received clay was dried, crushed in a laboratory pulveriser and ground in a ball mill. It was later sieved through a $30 \mathrm{~mm}$ sieve and the oversized that is predominantly silica was rejected. The silica was washed and dried to remove impurities that may lower the refractoriness of the ramming mass final mixes. The mica was washed and dried to remove organic impurities and clay. Milling in a ball mill was done. The mica was then sieved through a $300 \mu \mathrm{m}$ sieve.

\subsubsection{Chemical analysis of the raw materials}


The chemical analysis of the raw materials was done using the atomic Absorption spectrometer (AAS) and the results obtained are presented in Table 1.

\subsubsection{Particle size analyses}

The particle size analysis of silica was done using the American Foundrymen Society (AFS) Standard. The results of the analysis and the particle size distribution of other materials are presented in Table 2.

\subsubsection{Test sample preparation}

The various mixes prepared were mixed using the laboratory sand mixer. Each composition is first mixed in the dry state for a period of 10 mins to facilitate thorough mixing. Water was then added gradually to the dry powder and the mixing continued for another $20 \mathrm{mins}$. At this point, no dry powder was left. The mixed sample was then withdrawn form the machine. Ramming of the sample was made to the AFS specification of $\Phi 50$ x $50 \mathrm{~mm}$ height. Samples were dried in a laboratory oven at a temperature of $120^{\circ} \mathrm{C}$ for $130 \mathrm{mins}$ and then left to cool overnight. Firing of the samples were done at the rate of $5^{\circ} \mathrm{C} / \mathrm{min}$ to a temperature of $1100^{\circ} \mathrm{C}$.

\subsection{Testing of Samples}

\subsubsection{Shrinkage test}

This was done to determine the volumetric firing shrinkage of the fired samples. The procedure involved taking the dimensions of the sample before and after firing. The difference in the dimension was calculated from the expression:

$$
V S=\frac{v 1-v 2}{v 1} \times 100 \%
$$

Where $V S=$ volumetric shrinkage

$v 1=$ initial volume

$v 2=$ final volume

\subsubsection{Apparent porosity}

The weight of each fired sample was taken and recorded as $D$. Each sample was immersed in water for $6 \mathrm{hrs}$ to soak and weighed while been suspended in air. The weight was recorded as $W$. Finally, the specimen was weighed when immersed in water. This was recorded as $S$. the apparent porosity was then calculated from the expression:

$$
p=\frac{[w-D]}{[w-S]} \times 100 \%
$$




\subsubsection{Loss on ignition (LOI)}

This determines the percentage weight reduction of the total weight of the sample. The percentage loss in weight of each sample was determined by the difference between the weight before firing and the weight thereafter. This represents the loss on ignition at that temperature. The loss on ignition was calculated from the equation:

$$
L O I=\frac{m 1-m 2}{m 1} \times 100 \%
$$

Where $L O I=$ Loss on ignition

$m 1=$ weight of sample before firing

$m 2=$ weight of sample after firing

\subsubsection{Cold compression strength}

This was done to determine the compression strength to failure of each sample, an indication of its probable performance under load. Each sample was placed between two plates of the compression strength tester. This was followed by the application of a uniform load to it. The load at which a crack appears on the sample was noted and the cold compression strength CCS is calculated from the equation:

$$
C C S=\frac{\text { Load to Fracture }}{\text { Surface Area of Sample }} K G c m-2
$$

\subsubsection{Thermal shock resistance}

Each sample dimensioning $\Phi 50 \mathrm{~mm} \pm 0.5 \mathrm{~mm}$ and $50 \mathrm{~mm} \pm 0.5 \mathrm{mmheight}$ was placed in an electrically heated furnace to attain the test temperature of $1100^{\circ} \mathrm{C}$. Each sample was then withdrawn from the furnace and held for 10minutes. The procedure was repeated until an appearance of a crack was visible. The number of cycles necessary to cause a crack was recorded for each of the samples and taken as a measure of its thermal shock resistance.

\subsubsection{Refractoriness}

This was done to determine the temperature at which each test sample would fuse. Each test sample was placed in the furnace and the temperature was raised to $1000^{\circ} \mathrm{C}$. The sample was then observed to check for fusion. The process was repeated by increasing the temperature at $50^{\circ} \mathrm{C}$ interval until fusion was observed.

In the course of the experiment, the following parameters were studied:

(a) The effect of addition of silica on the drying properties of Ikere-Ekiti clay

(b) The effect of addition of mica on the green compression strength and drying properties of the 
silica-clay mixture

(c) the effect of binders (bentonite and Durax) on the properties of an optimum clay-silica-mica mix

\section{RESULTS}

(a) The result of the chemical analysis of the raw materials is presented in Table1.

Table 1: Chemical Analysis of the Raw Materials

\begin{tabular}{|c|c|c|c|c|c|}
\hline \multirow[t]{2}{*}{$\begin{array}{l}\text { Chemical } \\
\text { Compound }\end{array}$} & \multicolumn{5}{|c|}{$\begin{array}{c}\text { Composition } \\
\text { (\%) }\end{array}$} \\
\hline & $\begin{array}{l}\text { Ikere-Ekiti } \\
\text { clay }\end{array}$ & Silice & $\begin{array}{c}\text { Ijero-Ekiti } \\
\text { mica }\end{array}$ & Durax & Bentonite \\
\hline $\mathrm{SiO}_{2}$ & 46.28 & 95.26 & 50.87 & 15.43 & 55.4 \\
\hline $\mathrm{Al}_{2} \mathrm{O}_{3}$ & 27.71 & 1.22 & 33.50 & 34.13 & 23.1 \\
\hline $\mathrm{Fe}_{2} \mathrm{O}_{3}$ & 5.84 & 0.64 & 0.184 & 5.64 & 4.4 \\
\hline $\mathrm{CaO}$ & 1.81 & 0.01 & 1.57 & 21.82 & 0.2 \\
\hline $\mathrm{K}_{2} \mathrm{O}$ & 0.85 & 0.004 & 0.85 & 0.85 & 3.0 \\
\hline $\mathrm{MgO}$ & 3.65 & 1.22 & 1.30 & 2.18 & 2.5 \\
\hline $\mathrm{Na}_{2} \mathrm{O}$ & 0.5 & 0.69 & 0.95 & 0.13 & 3.0 \\
\hline $\mathrm{MnO}$ & 0.74 & 0.35 & 0.57 & 1.87 & 0.02 \\
\hline LoI & 12.6 & 0.56 & 10.20 & 17.67 & 7.8 \\
\hline Others & 0.02 & 0.040 & 0.006 & 0.28 & 0.58 \\
\hline Total & 100 & 100 & 100 & 100 & 100 \\
\hline
\end{tabular}

(b) The results of the sieve analysis and the particle size distribution of the raw materials is presented in Table 2 .

Table 2: Particle Sizes of Raw Materials

\begin{tabular}{||l|c||}
\hline \multicolumn{1}{|c|}{ Raw Material } & Particle Size \\
\hline Ikere Ekiti Clay & $<300 \mu \mathrm{m}$ \\
\hline Ijero mica & $<300 \mu \mathrm{m}$ \\
\hline Durax & $<300 \mu \mathrm{m}$ \\
\hline Bentonite & $<300 \mu \mathrm{m}$ \\
\hline Silica & AFS GFN 3.81 \\
\hline
\end{tabular}


(c) The results of the various tests carried out to determine the characteristics of the test specimens are presented in Figs. 1 to 9.

(d) The result of the thermal shock resistance and the refractoriness values of samples are presented in Tables 3 and 4 .

Table 3: Thermal Shock Resistance of Optimum Compositions at $\mathbf{1 1 0 0}^{\circ} \mathrm{C}$

\begin{tabular}{|l|l|l|}
\hline Sample & Number of Cycles withstood & Comment* \\
\hline Clay-Silica-mica-bentonite & $>30$ & Excellent \\
\hline Clay-Silica-Mica-Durax & $>30$ & Excellent \\
\hline
\end{tabular}

* Gilchrist, 1977

Table 4: Refractoriness Values of Optimum Compositions

\begin{tabular}{|l|l|}
\hline Sample & Refractoriness $\left({ }^{\mathbf{0}} \mathbf{C}\right)$ \\
\hline Clay-Silica-mica-bentonite & 1500 \\
\hline Clay-Silica-Mica-Durax & 1500 \\
\hline
\end{tabular}

\section{DISCUSSIONS}

\subsection{The Effect of Addition of Silica on the Properties of Ikere-Ekiti Clay}

It was observed that the Ikere-Ekiti clay mixed with $10 \%$ water cracked during the drying process and firing operations at a temperature of $120^{\circ} \mathrm{C}$ and $1000^{\circ} \mathrm{C}$ respectively. This is due to the volumetric shrinkage, which followed the drying and the firing operations. Therefore, to reduce the shrinkage and avoid cracks, free silica of AFS GFN 3.81 was added in steps of 2\% $\mathrm{w} / \mathrm{w}$ of silica, keeping the water content constant at $10 \%$ (Fig. 1).

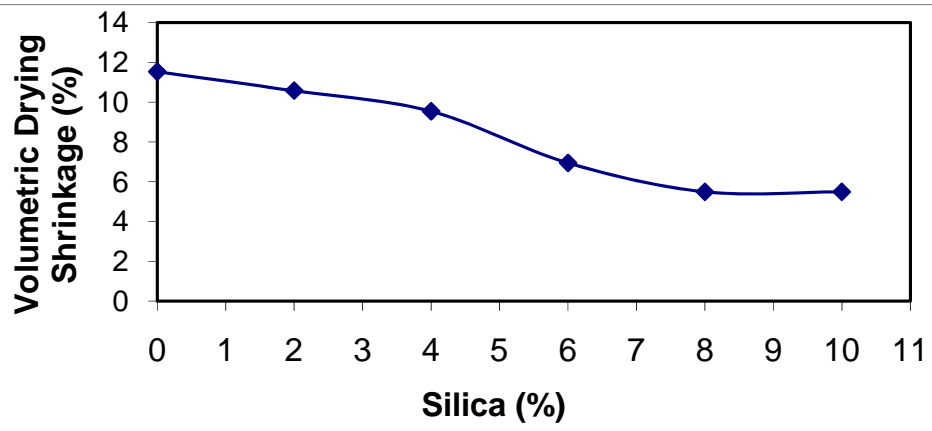

Fig 1: The Effect of Silica Addition on the Volumetric Drying Shrinkage of Ikere-Ekiti Clay

The choice of this grain size is due to the fact that it has been established that free silica of finer grain size lowers the refractoriness of clay by reacting with the alkali and the alkaline earth oxides in clay due to larger surface area, which will increase the tendency for softening (Adeoye, 
1986). It was observed that compositions with $10 \%$ silica and above showed no crack. This is due to the low volumetric shrinkage after firing. The shrinkage was reduced from $11.5 \%$ in $100 \%$ Ikere-Ekiti clay to $5.9 \%$ in $90 \%$ clay-10\% silica mix. Since the $5.9 \%$ value is acceptable for ramming purposes (Chesti, 1986), the 10\% silica:90\% clay mix was chosen for further investigations. The choice was arrived at based on its low volumetric change after firing and because of the fact that higher silica content will lower the cold compression strength of the mix and present a rough surface to the rammed samples. It has been established that rough surfaces usually lower the abrasion resistance of monolithic working surfaces (Semler, 2002).

\subsection{Effect of Addition of Mica on the Green Compression Strength and the Drying Behavior of Clay-Silica System}

The effect of mica addition of the green compression strength of clay- silica system is given in Fig 2. It was observed that the mica addition to the clay-silica-system causes progressive decrease in the green compression strength of the mix.

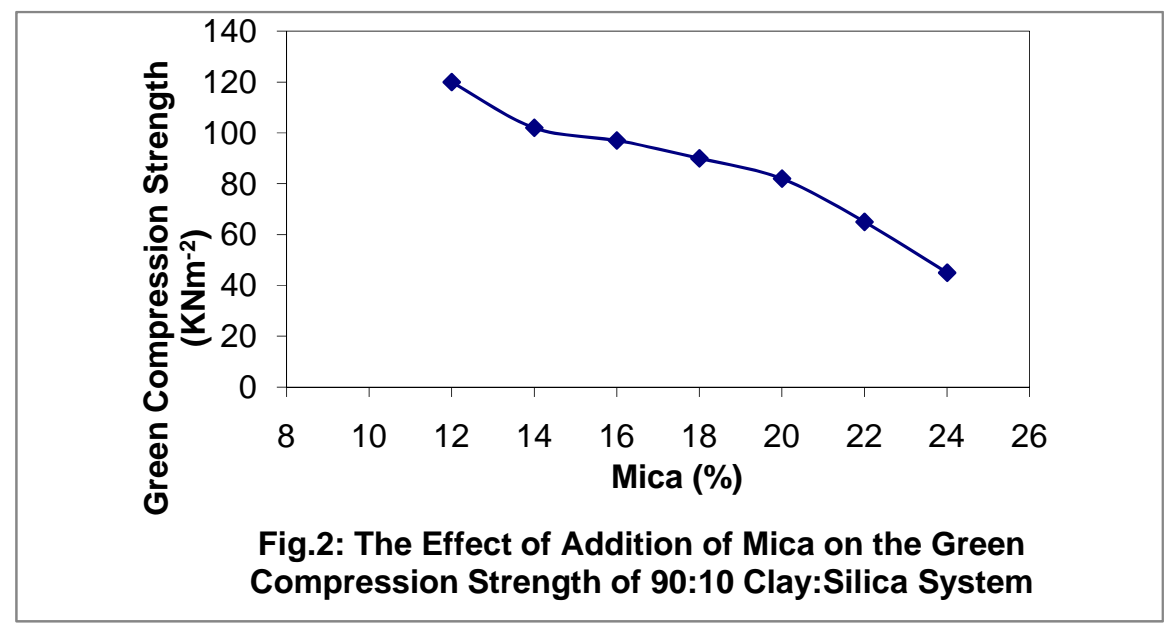

Also, fine cracks appeared on the surface of samples with mica content exceeding $20 \%$. This observed behavior is as a result of the inert surface of mica to water film, which tends to cause cleavage between the mica particles, silica and clay.

Fig. 3 shows the variation of ramming cycle with apparent porosity.

Figs 4 and 5 show the drying properties of the clay-silica-mica system, while Fig. 6 presents the loss on ignition at different temperatures. The clay-silica-mica (90:10:20) system was therefore chosen for further investigations. 


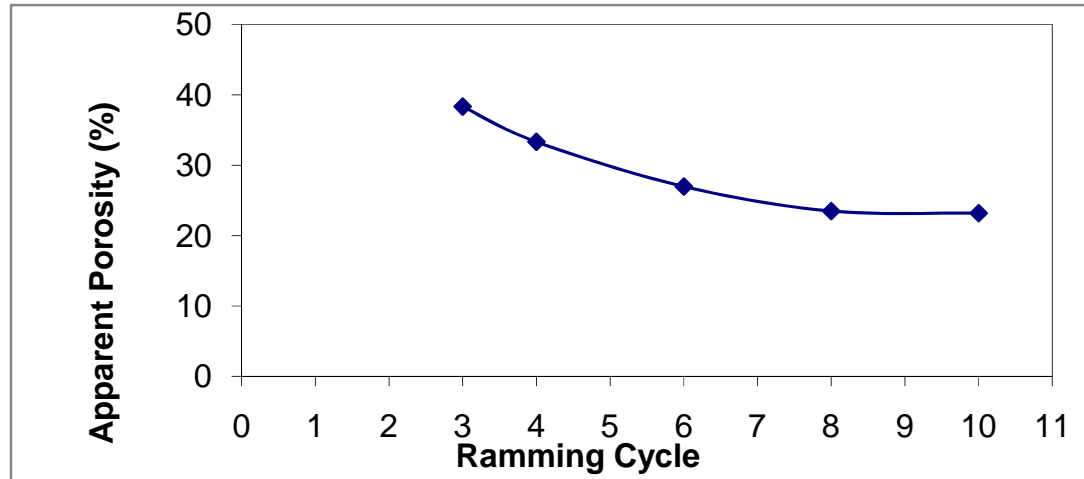

Fig. 3: The Effect of Ramming Pressure on the Apparent Porosity of Clay Silica-Mica system

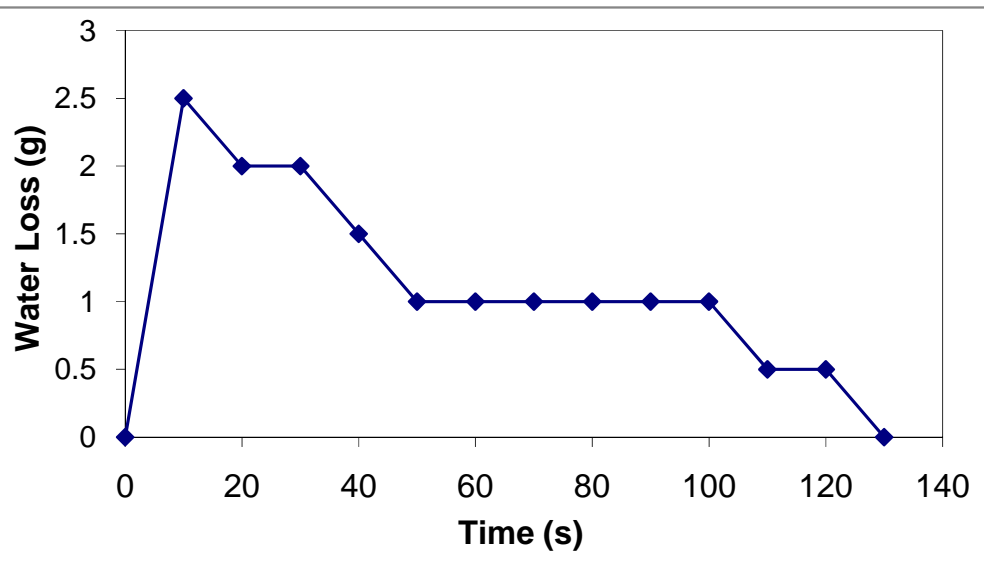

Fig. 4: Drying Rate of Clay-Silica-Mica System

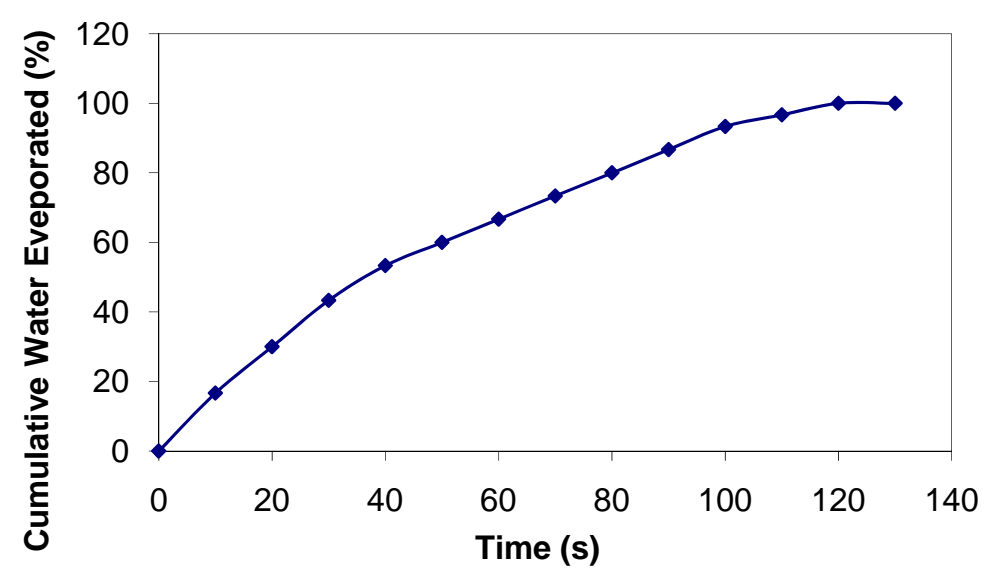

Fig. 5: Cumulative Water Loss in Clay-Silica-Mica System During Drying 


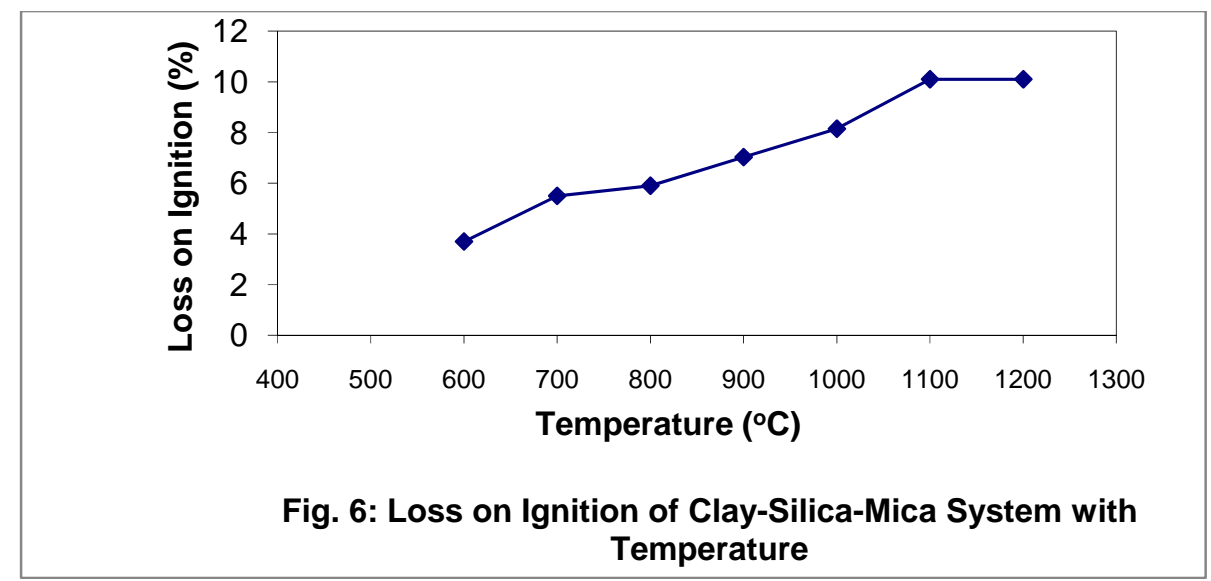

\subsection{Effect of Addition of Binders on Some Properties of Clay-Silica-Mica System}

Measurements were taken to determine the effect of bentonite and Durax on some properties of clay-silica-mica system (90-10-20). The samples were subjected to eight ramming cycles to achieve apparent porosity of $23.1 \%$, which is comparable to that of aluminosilicate bricks (Gilchrist, 1977). Properties such as volumetric firing shrinkage, loss on ignition and apparent porosity were also determined. The results were presented in Figs. 7, 8, and 9.

It can be seen from Fig. 7 that an increase in bentonite addition content caused a slight decrease in volumetric firing shrinkage. This is due to the small particle size of bentonite, which causes closely packed aggregate resulting in reduction in firing shrinkage as bentonite content increases. On the other hand, increase in the amount of Durax initially led to decrease in volumetric firing shrinkage and thereafter remains constant.

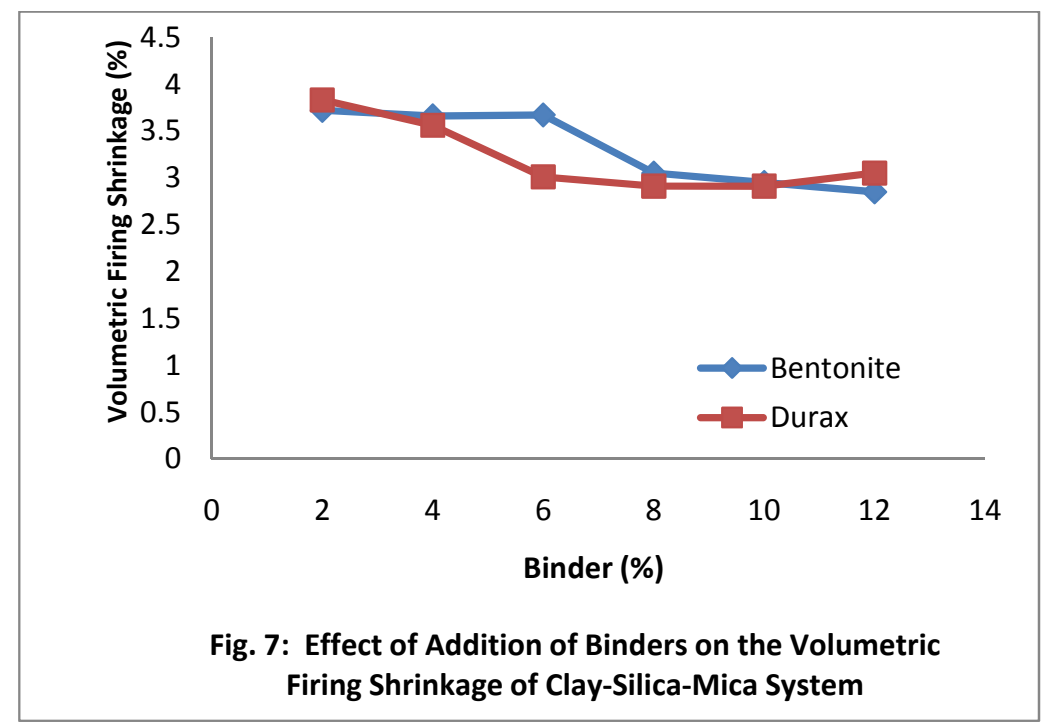


Fig. 8 presents the effect of binders on the loss on ignition of clay-silica-mica system. As can be seen from the curves, the loss on ignition remains fairly constant with increase in binder content. For the same percentage addition of Durax and bentonite, bentonite addition gave a higher value of loss on ignition.

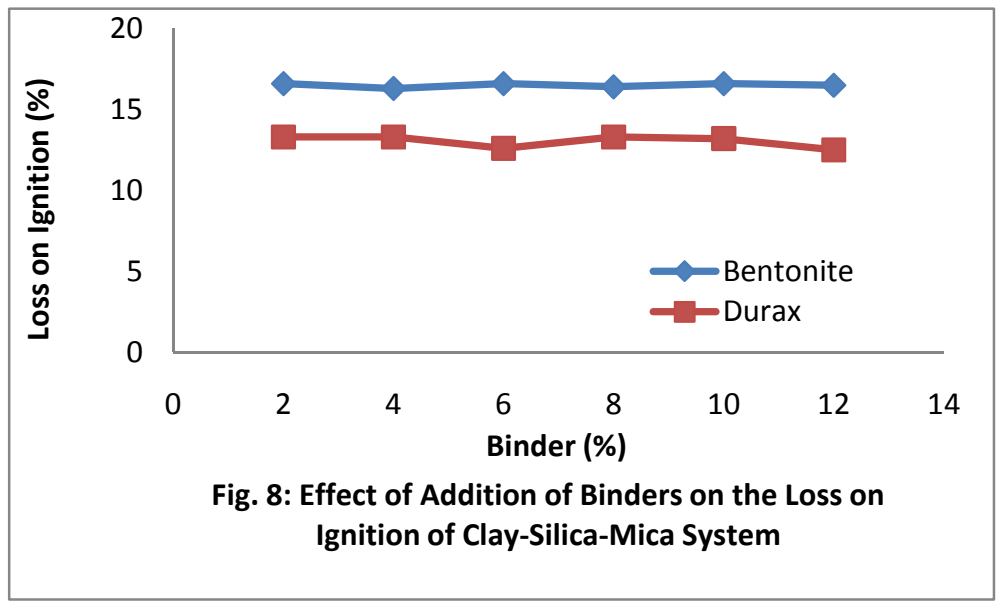

From Fig. 9, an increase in the amount of additives caused a corresponding increase in apparent porosity value of the samples. This is due to the small particle size of the additives, which caused a close packed aggregate in the structure of the rammed samples.

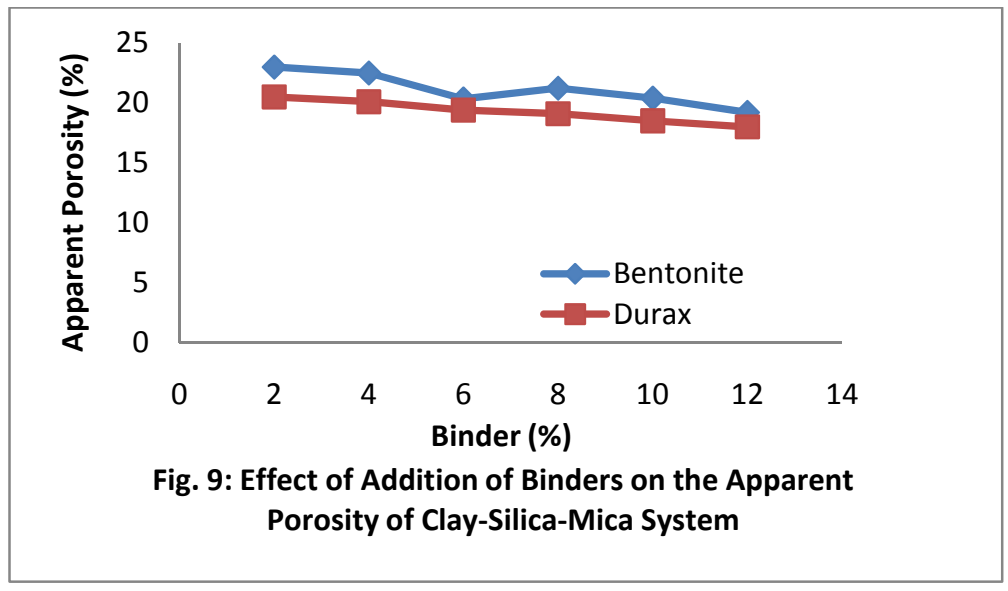

\section{CONCLUSION}

From the tests conducted, two optimal ratios of ramming mass could be recommended for use in lining melting furnaces for cast iron production such as rotary and crucible furnaces. These materials can also find applications in ceramic kilns and re-heating furnaces operating below $1500^{\circ} \mathrm{C}$. They could serve as a substitute for ramming mass in their category. 


\section{References}

Adeoye, M. O., (1986): Effect of Microstructures on the Thermal Properties of Refractory Materials, Unpublished M. Sc. Thesis, Obafemi Awolowo University, Ile-Ife.

Borode, J. O., Onyemaobi, O. O., and Omotoyinbo, J. A. (2000): Suitability of some Nigerian Clays as Refractory Raw Materials, Nigerian Journal of Engineering Management, Vol.3, pp1418.

Chesti, R. A. (1986): Refractories Manufacture, Properties and Applications, Eastern Economy Edition, Prentice-Hall, pp8-110.

Energy Efficiency Guide for Industry in Asia CUNEP (2006), Thermal Energy Equipment:

Furnaces and Refractories www.energyefficiencyasia.org accessed on-line $23^{\text {rd }}$ June, 2008.

Gilchrist, J. D., (1977): Fuels Furnaces And Refractories, Pergamon press Ltd. London.

Hassan, S. B. (2001): Effect of Silicon Carbide on Some Refractory Properties of Kankara Clay, proceeding on Nigerian Metallurgical society.

Onyemaobi, O.O. (2004): Assessment of Some Refractory Properties of Some Local Clays for Foundry Usage, Inter. Res. Jour. in Engr. Sc. \& Tech (IREJEST), Vol.1, No.2, 2004, 105-114.

Semler, C. E., (2002): Refractories Review; The Importance of Microstructure, www.ceramicindustry.com

Ugheoke, B. I., Onche, E. O., Namessan, O. N. and Asikpo, G. A., (2006): Property Optimization of Kaolin - Rice Husk Insulating Fire - Bricks, Leonardo Electronic Journal of Practices and Technologies, Issue 9, July-December 2006,p. 167-178 http://lejpt.academicdirect.org accessed on-line $23^{\text {rd }}$ June, 2008. 